\title{
Control Strategy for Power Distribution in Dual Motor Propulsion System for Electric Vehicles
}

\author{
Pedro Daniel Urbina Coronado and Horacio Ahuett-Garza \\ Escuela de Ingeniería y Ciencias, Tecnológico de Monterrey, 64849 Monterrey, NL, Mexico \\ Correspondence should be addressed to Pedro Daniel Urbina Coronado; pd.urbina.phd.mty@itesm.mx
}

Received 5 September 2015; Accepted 2 November 2015

Academic Editor: Shengbo Eben Li

Copyright (C) 2015 P. D. Urbina Coronado and H. Ahuett-Garza. This is an open access article distributed under the Creative Commons Attribution License, which permits unrestricted use, distribution, and reproduction in any medium, provided the original work is properly cited.

\begin{abstract}
Electric Vehicles with more than one electric motor can offer advantages in saving energy from the batteries. In order to do that, the control strategy plays an important role in distributing the required torque between the electric motors. A dual motor propulsion system with a differential transmission is simulated in this work. A rule based control strategy for this propulsion system is proposed and analyzed. Two parameters related to the output speed of the transmission and the required torque are used to switch the two modes of operation in which the propulsion system can work under acceleration. The effect of these parameters is presented over the driving cycles of NEDC, UDDS, and NYCC, which are followed using a PID controller. The produced energy losses are calculated as well as an indicator of drivability, which is related to the difference between the desired speed and the actual speed obtained. The results show that less energy losses are present when the vehicle is maintained with one electric motor most of the time, switching only when the extended speed granted by the second motor is required. The propulsion system with the proposed control strategy represents a feasible alternative in the spectrum of sustainable transportation architectures with extending range capabilities.
\end{abstract}

\section{Introduction}

Compared with propulsion systems based on the Internal Combustion Engine (ICE), the electric propulsion system offers advantage in the efficiency in which the energy is transformed into rotating movement. Typical Electric Vehicle (EV) propulsion systems provide efficiencies between 53\% and $77 \%$, which are superior when compared to propulsion systems based on ICEs, with efficiencies between 13\% and $20 \%$ [1]. However, the capacity to store energy in an Electric Vehicle continues to represent a limitation for a more widespread use of EVs. With current technologies, the amount of energy that can be carried lies in a range between 100 and $250 \mathrm{Wh} / \mathrm{kg}[2,3]$, significantly smaller than the amount of energy stored in fossil fuels $15 \mathrm{kWh} / \mathrm{kg}$ [4]. This fact, combined with long charging periods and elevated cost, results in EVs with limited driving range that cannot compete with ICE cars.

To address this issue, several research lines have been explored. Lightweight materials [5], new battery technologies $[3,6]$, and more efficient motors and power electronics [7] can be counted among the possible improvements. In parallel with those research lines, it has been found that architectures that depart from the traditional electric powertrain can offer a more efficient use of the limited energy stored in the batteries. In such systems, two or more electric motors are used in combination with a planetary gear train, which allows the load to be distributed among the motors. This provides properties of speed ratios that cannot be achieved by conventional transmissions. The control strategy for the power distribution of energy between the motors is a decisive factor in the minimization of power losses of the propulsion system.

In the work of Zhang and coworkers [8], the dual motor coupling propulsion system (DMCPS) is presented. The DMCPS can work with one or two electric motors. The shift between one or two motors is produced when the main motor achieves certain speed, which is then maintained constant, and, from that point, the vehicle speed is regulated only by a smaller auxiliary motor. However, when there is a speed differential between the branches of planetary systems, there are also differences in the torque ratios between the power 
sources, an effect that was not specified in the cited article. Efficiency analysis and EV driving range simulations have found that efficiency and range are improved if the dual motor type of propulsion system works either with one motor and the other motor locked or with the two motors at the same speed [9]. The operation of the two motors at different speeds can be used as a transition, as we propose in the present work. In the work of Wang and Sun [10], a dual motor propulsion system is also analyzed with an optimization of the components of the powertrain; however details of the control strategy of operation of the two motors were not provided.

The proposed power split control strategy has the capacity to achieve vehicle speeds either working only with one electric motor, working with two electric motors at the same speed, or working with two electric motors at different speeds. The goal is to analyze the input information that the control strategy requires in real time to obtain lower energy losses in the propulsion system during the vehicle acceleration, with the best drivability possible. Due to its simplicity and practicality, a rule based algorithm was chosen to design the control strategy over other popular alternatives like dynamic programming $[8,11]$ or extremum seeking algorithm [12] whose implementation could be unfeasible or computationally expensive.

Considering the mentioned control strategies and optimizations in powertrains with more than one electric motor, this work aims to contribute with the design of a power split control strategy for a dual motor type of propulsion system for EVs, implementable in real time, which depend on the monitoring of the driver torque request and the vehicle speed. Also, the proposed control strategy was modelled and simulated over driving cycles to analyze the effect of its control parameters on the energy losses and drivability.

The organization of this work is as follows. Section 2 describes the powertrain architecture and Section 3 presents the modelling of its components. Section 4 describes the design of the control strategy. Section 5 provides the results of the proposed control strategy and the effects of the input parameters of the control strategy on energy losses and drivability. Section 6 provides the conclusions of this study.

\section{Powertrain Architecture}

The powertrain used in this work is presented in the schematic displayed in Figure 1. The first differential (D1) is composed of side gears 1 and 2 (SG1 and SG2), a carrier and planetary gears, and a ring gear (RG) which outputs the torque. The torque is transmitted through a reduction gear and from there to a second differential (D2), which transmits the power to the wheels.

The figure shows that the torque request is sent to the embedded system, which transmits the torque request to the two motors. The control strategy is programmed in the embedded system, which is in charge of the decision of when it is more convenient to use one or both motors according to the conditions of speed and available power. When both motors are used, the torque is transmitted from them to D1. When only one motor is used, one of the motor locks

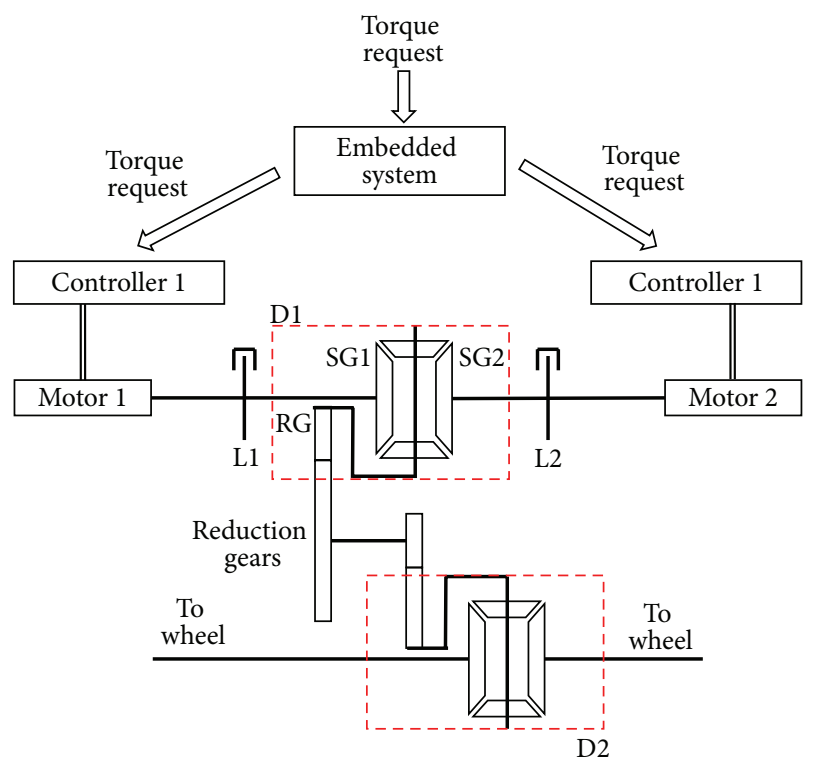

FIGURE 1: Diagram of the propulsion module that shows the internal component of the transmission (differentials and gear reduction) and the motors, controllers, and embedded system.

(labeled in the diagram as L1 or L2) is activated to prevent the rotation of the idle motor. The described powertrain was simulated to account for the power losses incurred in the electric motors. The control strategy objective is to provide the necessary power, considering the torque request and current speed, by choosing the operation mode (one or two motors) that provides less energy losses. The models used for the simulation are described in Section 3.

\section{Component Modelling}

The EV is modelled using the conventional longitudinal dynamics equations for loads caused by rolling resistance $\left(F_{\mathrm{rr}}\right)$, aerodynamic $\operatorname{drag}\left(F_{\mathrm{ad}}\right)$, hill climbing $\left(F_{\mathrm{hc}}\right)$, and inertial forces $\left(F_{\text {la }}\right)$ in

$$
\begin{aligned}
& F_{\mathrm{rr}}=C_{\mathrm{rr}} \cdot g \cdot m \cdot \cos \theta, \\
& F_{\mathrm{ad}}=\frac{1}{2} \cdot \rho \cdot C_{a} \cdot A \cdot\left(\frac{d x}{d t}\right)^{2}, \\
& F_{\mathrm{hc}}=g \cdot m \cdot \sin \theta, \\
& F_{\mathrm{la}}=m \cdot \frac{d^{2} x}{d t^{2}} .
\end{aligned}
$$

For the rolling resistance force, $C_{\mathrm{rr}}, g, m$, and $\theta$ are the rolling resistance coefficient, gravity, vehicle mass, and slope angle, respectively. For the aerodynamic drag, $\rho, C_{a}, A, x$, and $t$ are the air density, aerodynamic drag coefficient, frontal area, displacement, and time, respectively. These forces are added to obtain the traction force $\left(F_{\mathrm{tr}}\right)$ in

$$
F_{\mathrm{tr}}=F_{\mathrm{rr}}+F_{\mathrm{ad}}+F_{\mathrm{hc}}+F_{\mathrm{la}} \text {. }
$$


TABLE 1: Cases and conditions to obtain the output torque. The columns of L1 and L2 (locks 1 and 2) express whether the lock is activated (1) or deactivated $(0)$.

\begin{tabular}{|c|c|c|c|c|c|}
\hline Operation mode $(\mathrm{OM})$ & L1 & $\mathrm{L} 2$ & $\begin{array}{r}\text { Condition } \\
\text { Driving link }\end{array}$ & Driven link & Output torque $\left(T_{\mathrm{D} 1}\right)$ \\
\hline 1 & 0 & 1 & SG1 & $\mathrm{RG}$ & $T_{\mathrm{EM} 1} \cdot 2$ \\
\hline 2 & 0 & 0 & SG1, SG2 & RG & $T_{\mathrm{EM} 1} \cdot\left(2 \cdot \omega_{\mathrm{EM} 1} /\left(\omega_{\mathrm{EM} 1}+\omega_{\mathrm{EM} 2}\right)\right)+T_{\mathrm{EM} 2} \cdot\left(2 \cdot \omega_{\mathrm{EM} 2} /\left(\omega_{\mathrm{EM} 1}+\omega_{\mathrm{EM} 2}\right)\right)$ \\
\hline 3 & 0 & 0 & SG2 & SG1 & 0 \\
\hline
\end{tabular}

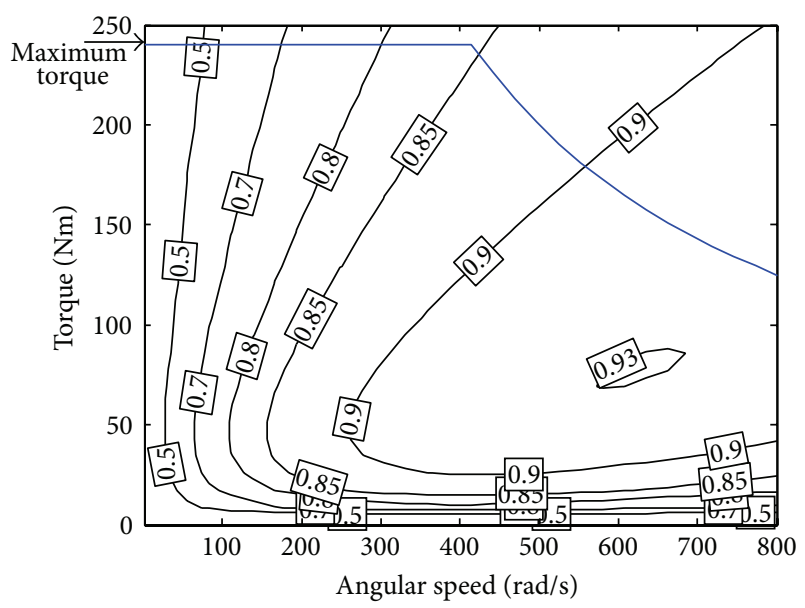

FIGURE 2: Efficiency map used to represent the power losses incurred in the electric motors.

The load torque transmitted to differential $1\left(T_{\mathrm{tr}}\right)$ passing through differential 2 and the gear reduction is presented in (3), where $R_{w}$ is the wheels radius and $G_{r}$ is the overall gear ratio:

$$
T_{\mathrm{tr}}=F_{\mathrm{tr}} \cdot R_{w} \cdot G_{r}
$$

The model for the electric motor considers the power losses as a function of the torque and speed [13-16]. The efficiency of the motor $\left(\eta_{\mathrm{EM}}\right)$ is given by (4) in which $T_{\mathrm{EM}}$ and $\omega_{\mathrm{EM}}$ are the torque and the angular speed of the electric motor. The parameters $k_{c}, k_{i}, k_{\omega}$, and $C$ take the values 0.3 , $0.01,0.000005$, and 600 , respectively, to simulate a $100 \mathrm{~kW}$ induction motor [13]. The efficiency of both electric motors $\left(\eta_{\mathrm{EM} 1}\right.$ and $\left.\eta_{\mathrm{EM} 2}\right)$ in this study is calculated using (4). Figure 2 represents the efficiency map of the motor in its operation range and the line of maximum torque. Consider

$$
\begin{aligned}
& \eta_{\mathrm{EM}} \\
& =\frac{T_{\mathrm{EM}} \cdot \omega_{\mathrm{EM}}}{T_{\mathrm{EM}} \cdot \omega_{\mathrm{EM}}+k_{c} \cdot T_{\mathrm{EM}}{ }^{2}+k_{i} \cdot \omega_{\mathrm{EM}}+k_{\omega} \cdot \omega_{\mathrm{EM}}{ }^{3}+C} .
\end{aligned}
$$

In this case, the same characteristics for the two electric motors were used. The output angular speed of differential $1\left(\omega_{\mathrm{D} 1}\right)$ is a function of the speed of electric motors 1 and 2 $\left(\omega_{\mathrm{EM} 1}\right.$ and $\left.\omega_{\mathrm{EM} 2}\right)$ as shown in

$$
\omega_{\mathrm{D} 1}=\frac{\omega_{\mathrm{EM} 1}+\omega_{\mathrm{EM} 2}}{2} .
$$

The output torque of differential $1\left(T_{\mathrm{D} 1}\right)$ is a function of the torque of the electric motors $\left(T_{\mathrm{EM} 1}\right.$ and $\left.T_{\mathrm{EM} 2}\right)$ as shown in Table 1. According to the table, Operation Mode 1 (OM 1) corresponds to a situation in which lock 2 is actuated and, as a consequence, $\omega_{\mathrm{EM} 2}=0$. All the power for the vehicle is provided by electric motor 1 . In Operation Mode 2 (OM 2), both locks are deactivated and the vehicle is powered by both of the electric motors. In Operation Mode 3 (OM 3), both locks are deactivated but one of the motors is being driven by the other motor, and as a result $T_{\mathrm{D} 1}=0$ is obtained. This mode cannot accelerate the vehicle but can be useful in regulating the speed of the electric motors. The three modes are subjected to the condition of (6) which represents the energy balance of the differential:

$$
T_{\mathrm{D} 1} \cdot \omega_{\mathrm{D} 1}=T_{\mathrm{EM} 1} \cdot \omega_{\mathrm{EM} 1}+T_{\mathrm{EM} 2} \cdot \omega_{\mathrm{EM} 2} .
$$

According to OM 3, a condition in which one of the motors would operate at low speeds (and, e.g., at low efficiencies according to the efficiency map) is avoided.

The diagrams of Figure 3 show the way in which the acceleration is handled in this propulsion system. Figure 3(a) shows the case in which the driver provides a torque request $(\tau)$, which then produces a torque request for each motor $\left(\tau_{\mathrm{EM} 1}\right.$ and $\left.\tau_{\mathrm{EM} 2}\right)$ and ultimately produces an output angular speed $\left(\omega_{D 1}\right)$ which provides forward movement to the vehicle. In Figure 3(b) the driver is replaced by a PID controller which compares the obtained vehicle speed $(v(t))$ with a set point speed $\left(v_{\mathrm{SP}}(t)\right)$ defined by a driving cycle. The use of a driving cycle provides a predefined standard speed which can be used to produce comparisons in energy losses.

\section{Control Strategy for the Propulsion System}

The objective of the control strategy is to distribute the torque request signal to each electric motor. The control strategy starts working when a positive torque is requested to the powertrain to produce acceleration in the vehicle (when $\tau>$ $0)$. According to the current speed and the requested torque, a decision is made to calculate the torque request signal for each motor. The inequalities in (7) show the possible values that can be assigned for each torque request signal:

$$
\begin{aligned}
& 0<\tau<1, \\
& 0<\tau_{\mathrm{EM} 1}<1, \\
& 0<\tau_{\mathrm{EM} 2}<1 .
\end{aligned}
$$

The boundaries of the control strategy consider the limits of the parameters of the electric motors. The electric 


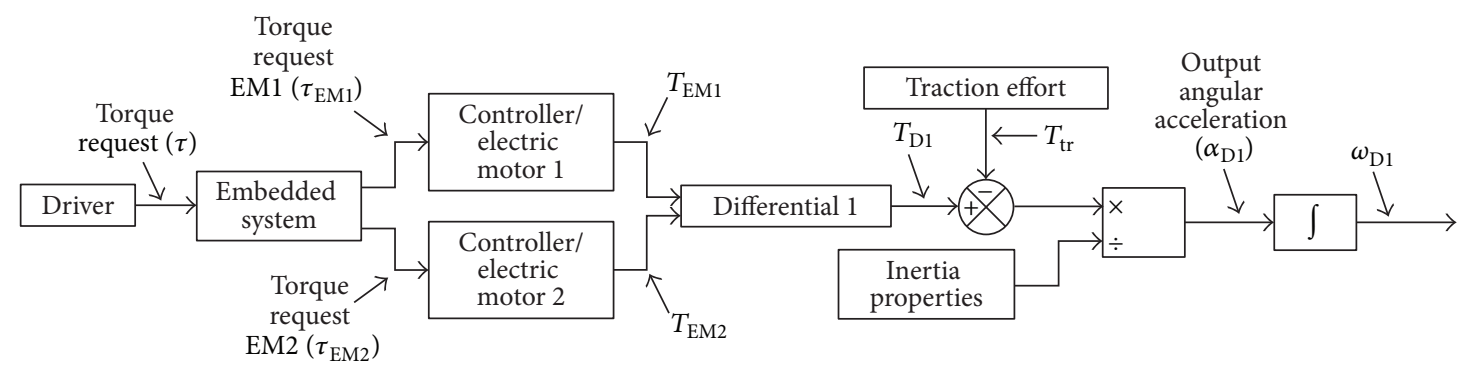

(a)

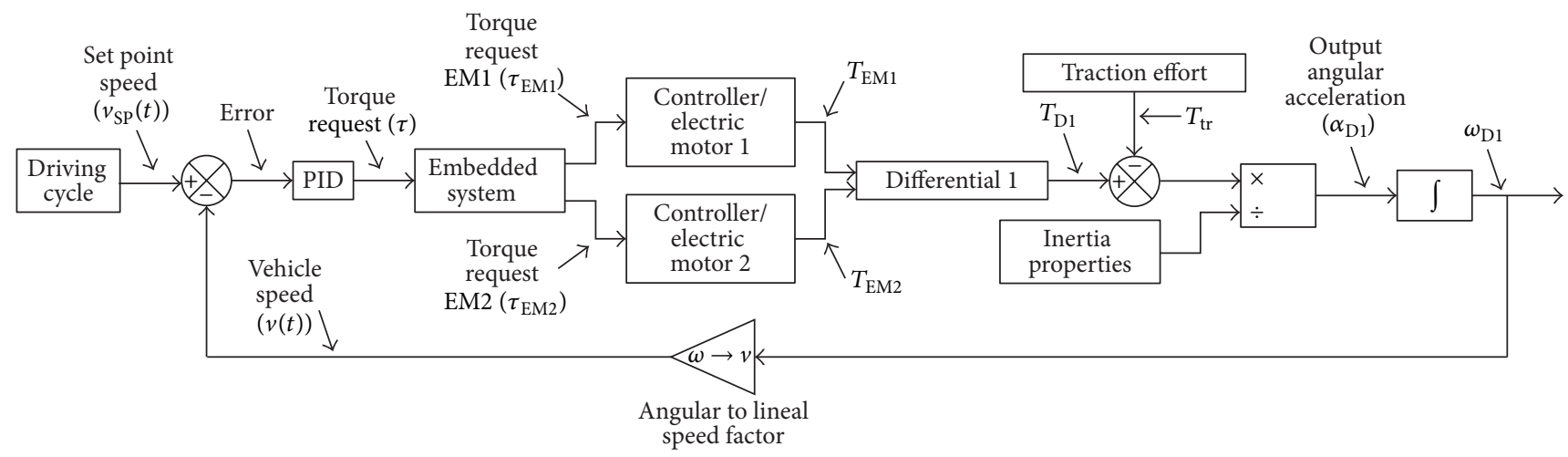

(b)

FIGURE 3: Block diagrams of (a) open loop control provided by a driver and (b) closed loop control to follow the speed of a driving cycle.

motor's maximum speed used for this study is $800 \mathrm{rad} / \mathrm{s}$. The maximum achievable torque for the electric motors is shown in Figure 2 in the torque limited zone $(0-415 \mathrm{rad} / \mathrm{s})$ and the power limited zone (415 rad/s-800 rad/s).

From (5), the maximum output speed for differential 1 $\left(\omega_{\mathrm{D} 1 \mid \max }\right)$ can be expressed according to (8) and (9) for OM 1 and OM 2 (previously defined in Table 1):

$$
\begin{aligned}
\text { OM 1: } \omega_{\mathrm{D} 1 \mid \max } & =\frac{\omega_{\mathrm{EM} 1 \mid \max }}{2}, \\
\text { OM 2: } \omega_{\mathrm{D} 1 \mid \max } & =\frac{\omega_{\mathrm{EM} 1 \mid \max }+\omega_{\mathrm{EM} 2 \mid \max }}{2} .
\end{aligned}
$$

The implication of (8) and (9) is that OM 2 enables higher speeds (by a factor of two) than what is possible to achieve by using OM 1 . The transition speed $\left(\omega_{1 \rightarrow 2}\right)$ is the speed $\omega_{\mathrm{D} 1}$ at which the powertrain changes the operation from one motor (OM 1) to two motors (OM 2). The possible values for $\omega_{1 \rightarrow 2}$ are limited by (8) which result in

$$
0 \leq \omega_{1 \rightarrow 2} \leq \frac{\omega_{\mathrm{EM} 1 \mid \max }}{2}
$$

The transition torque request $\left(\tau_{1 \rightarrow 2}\right)$ is the torque request signal at which the powertrain changes the operation from one motor to two motors. The possible values for $\tau_{1 \rightarrow 2}$ can be in the range $\{0,1\}$. The values chosen for $\omega_{1 \rightarrow 2}$ and $\tau_{1 \rightarrow 2}$ have an impact in the overall efficiency of operation of the powertrain and in the longitudinal dynamics of the vehicle, which is analyzed in the next section.

Figure 4 portrays the control logic in a flow diagram for the transitions between the previously defined operation
TABLE 2: Value of parameters for the simulation of the powertrain.

\begin{tabular}{lc}
\hline Symbol & Value \\
\hline$C_{\mathrm{rr}}$ & 0.007 \\
$\rho$ & $1.2 \mathrm{~kg} /\left(\mathrm{m}^{3}\right)$ \\
$R_{w}$ & $0.3 \mathrm{~m}$ \\
Motor maximum torque & $240 \mathrm{Nm}$ \\
$m$ & $1700 \mathrm{~kg}$ \\
$C_{a}$ & 0.2 \\
$G_{r}$ & $1 / 7$ \\
Motor maximum speed & $800 \mathrm{rad} / \mathrm{s}$ \\
$\theta$ & $0^{\circ}$ \\
$A$ & $2.11 \mathrm{~m}^{2}$ \\
$g$ & $9.81 \mathrm{~m} /\left(\mathrm{s}^{2}\right)$ \\
Motor maximum power & $100 \mathrm{~kW}$ \\
\hline
\end{tabular}

modes. According to the control logic, OM 3 is used to regulate the speeds of both motors until they are similar within certain range. For that reason OM 3 is used only to transition from OM 1 (motor 1 has speed but motor 2 is at rest) to OM 2 (both motors have speed). According to the control logic, when $\tau_{1 \rightarrow 2}$ and $\omega_{1 \rightarrow 2}$ are small, there are less chances for the powertrain to work on OM 1. On the contrary, when $\tau_{1 \rightarrow 2}$ and $\omega_{1 \rightarrow 2}$ are large, the manifestation of OM 3 and OM 2 is delayed.

\section{Effect of $\omega_{1 \rightarrow 2}$ and $\tau_{1 \rightarrow 2}$ on Acceleration and Power Losses}

To run simulations on the powertrain, the values of the parameters of the vehicle are shown in Table 2. 


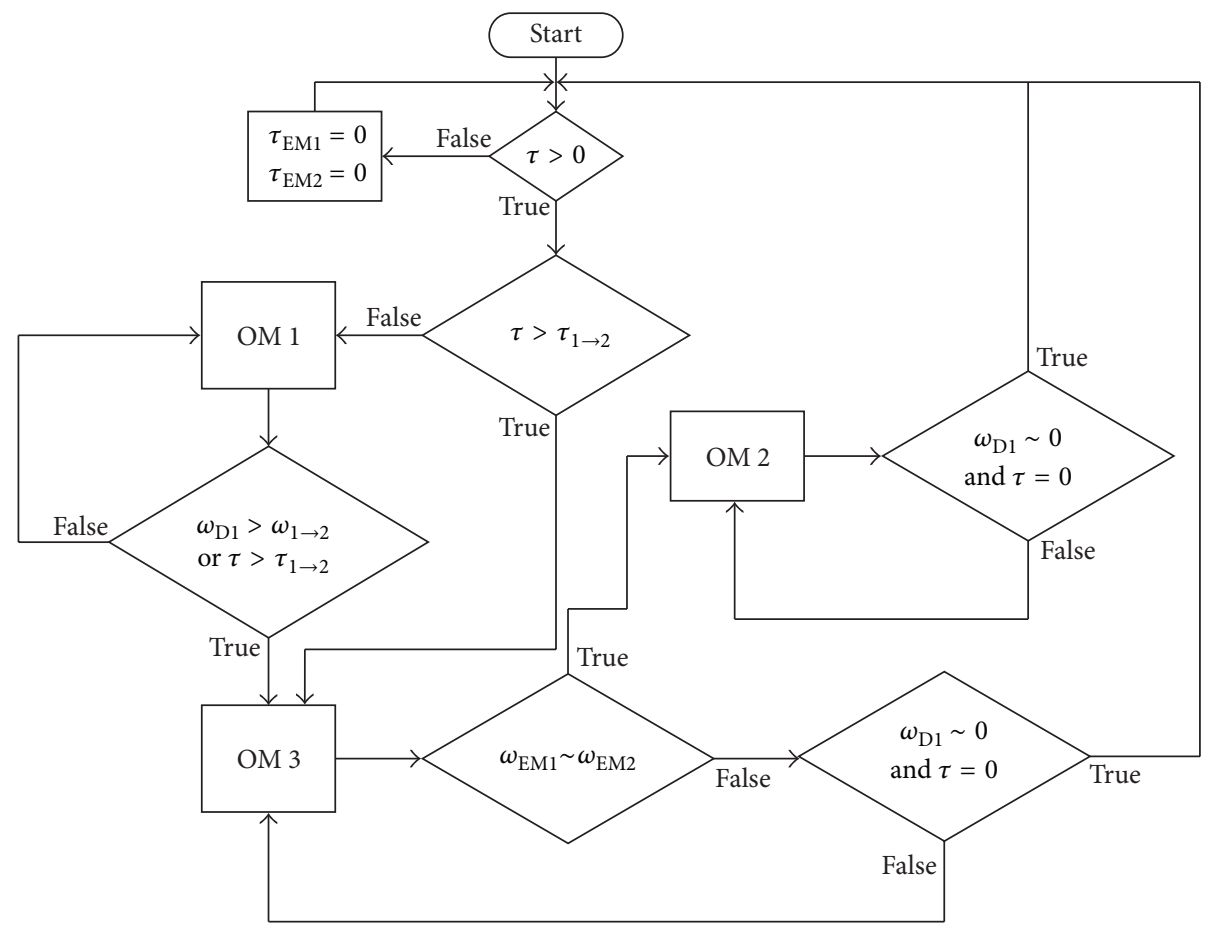

FIGURE 4: Flow diagram of the control strategy programmed in the embedded system.

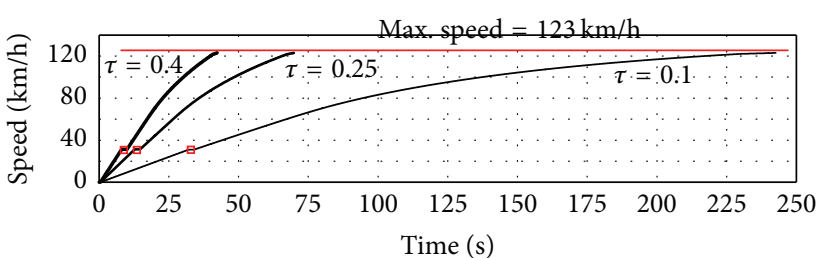

이 3

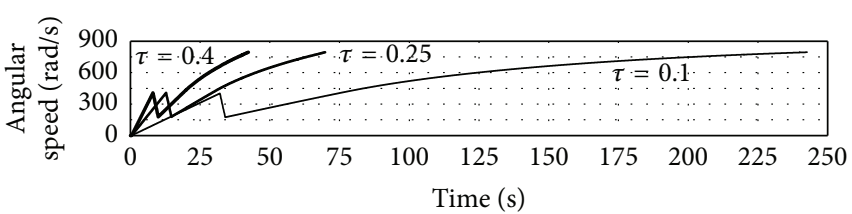

(b) Speed of electric motor 1

(a) Vehicle speed

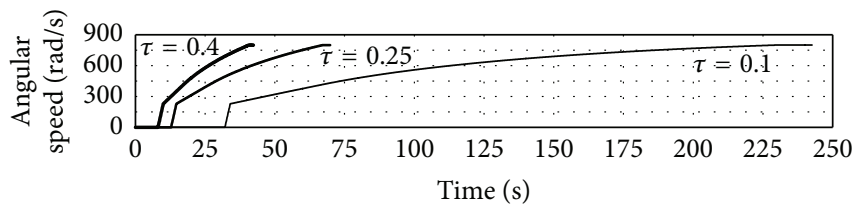

(c) Speed of electric motor 2

Figure 5: Speed of the vehicle (a), electric motor 1 (b), and electric motor 2 (c) for $\tau_{1 \rightarrow 2}=0.5$ and $\omega_{1 \rightarrow 2}=200 \mathrm{rad} / \mathrm{s}$.

Figure 5(a) shows a simulation of the vehicle speed with $\tau_{1 \rightarrow 2}=0.5$ and $\omega_{1 \rightarrow 2}=200 \mathrm{rad} / \mathrm{s}$. The three curves shown correspond to the torque requests $\tau=\{0.1,0.25,0.4\}$. The powertrain starts accelerating in $\mathrm{OM} 1$, then it transitions through a brief period of time in OM 3 (lasting $1.7 \mathrm{~s}$ ), and then it follows in OM 2. Figures 5(b) and 5(c) show the rotational speed of electric motors 1 and 2, respectively. The figures show that, in OM 1 , only electric motor 1 provides speed $\left(\omega_{\mathrm{EM} 1}\right)$ for the powertrain. In OM 3, $\omega_{\mathrm{EM} 1}$ decreases and $\omega_{\mathrm{EM} 2}$ increases until they have the same speed. After that, OM 2 begins to operate.
Figure 6(a) shows the vehicle speed when $\tau=0.25$ for two different values of $\tau_{1 \rightarrow 2}$. When $\tau_{1 \rightarrow 2}=0.15$ the acceleration is handled by the two motors (OM 2). When $\tau_{1 \rightarrow 2}=0.35$ the acceleration is first handled by only one motor (OM 1 ) and, after the transition speed $\left(\omega_{1 \rightarrow 2}=200 \mathrm{rad} / \mathrm{s}\right)$, the powertrain passes through OM 3 to OM 2 . According to the figure, when the powertrain is using one motor only, the vehicle achieves slightly higher acceleration; however, during $\mathrm{OM} \mathrm{3}$, the vehicle undergoes a period of coasting before the powertrain (in OM 2) accelerates the vehicle again. Figures $6(\mathrm{~b})$ and $6(\mathrm{c})$ show $\omega_{\mathrm{EM} 1}$ and $\omega_{\mathrm{EM} 2}$, respectively. The plots 


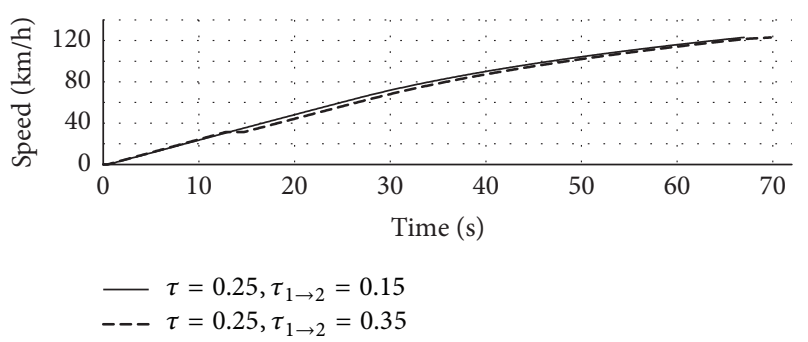

(a) Vehicle speed

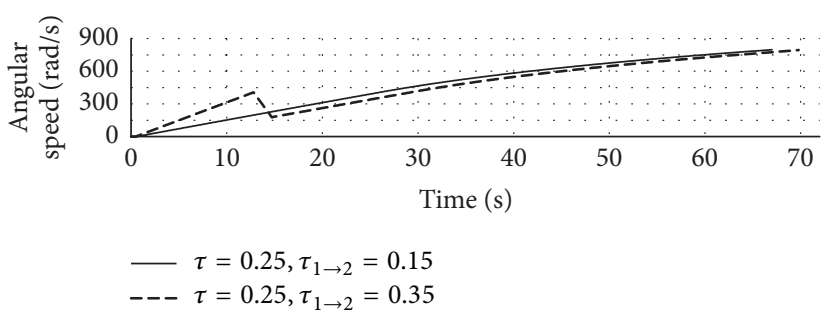

(b) Speed of electric motor 1

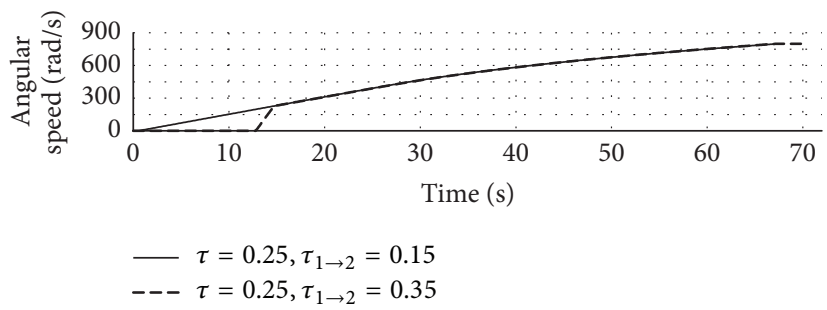

(c) Speed of electric motor 2

FIGURE 6: Effect of the transition torque request on the vehicle speed (a) and on the rotational speed of electric motors 1 (b) and 2 (c).

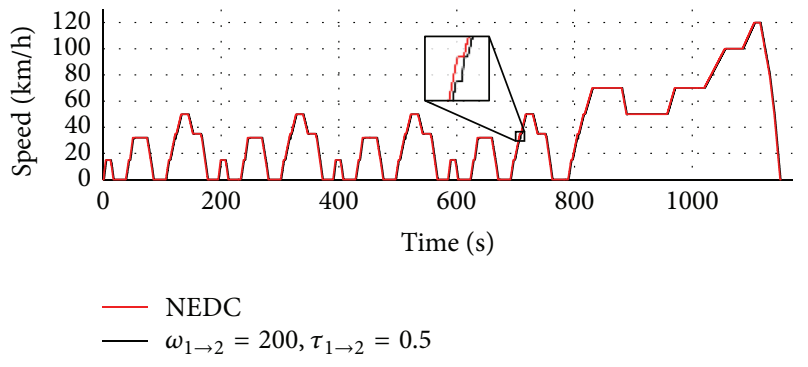

(a) Simulated vehicle speed following the NEDC driving cycle

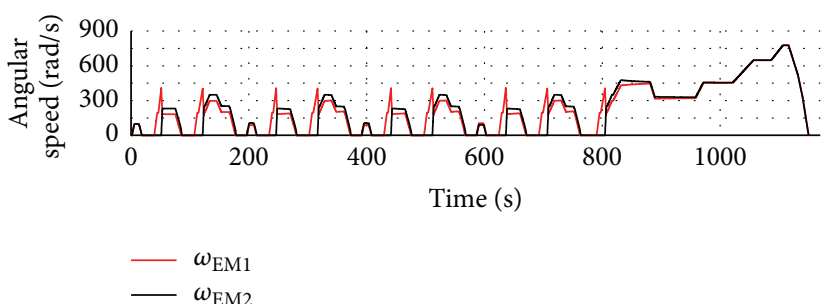

(b) Speed of electric motors

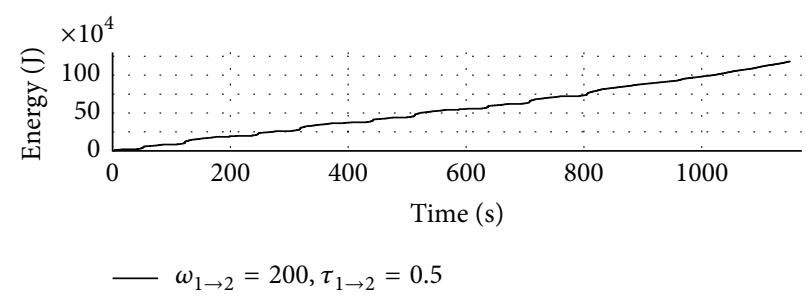

(c) Energy losses

FIGURE 7: Simulated vehicle speed and the speed of the NEDC driving cycle (a) and the rotational speed of the electric motors (b). The energy losses incurred are shown in (c).

corresponding to $\tau_{1 \rightarrow 2}=0.35$ show $\omega_{\mathrm{EM} 1}$ running at almost $400 \mathrm{rad} / \mathrm{s}$ just before the speed drops as a consequence of the start of OM 3. At that moment, $\omega_{\mathrm{EM} 2}$ starts to rise until the two speeds are the same. The plots corresponding to $\tau_{1 \rightarrow 2}=$ 0.15 show the powertrain operating in OM 2 all the time.

According to Figures 5 and 6, OM 3 produced a time in which the vehicle is not accelerated. Drivability, which "describes the driver's complex subjective perception of the interactions between driver and vehicle associated with the longitudinal acceleration aspects" [17], is affected by the implementation of OM 3. Next section continues the analysis of the effects of $\omega_{1 \rightarrow 2}$ and $\tau_{1 \rightarrow 2}$ on the energy losses and the drivability by using driving cycles.
5.1. Driving Cycle Simulation of the Control Strategy. The torque request $(\tau)$ necessary to follow the driving cycle was obtained using a PID. Figure 7(a) illustrates the New European Driving Cycle (NEDC) and the speed followed by the simulated vehicle using $\omega_{1 \rightarrow 2}$ and $\tau_{1 \rightarrow 2}$ with values of $200 \mathrm{rad} / \mathrm{s}$ and 0.5 , respectively. The control strategy follows closely the NEDC speed; however when OM 3 is present, an error occurred (the error was magnified in the figure for illustration purposes). The speed error $\left(e_{v}(t)\right)$ can be expressed as shown in

$$
e_{v}(t)=v_{\mathrm{SP}}(t)-v(t)
$$




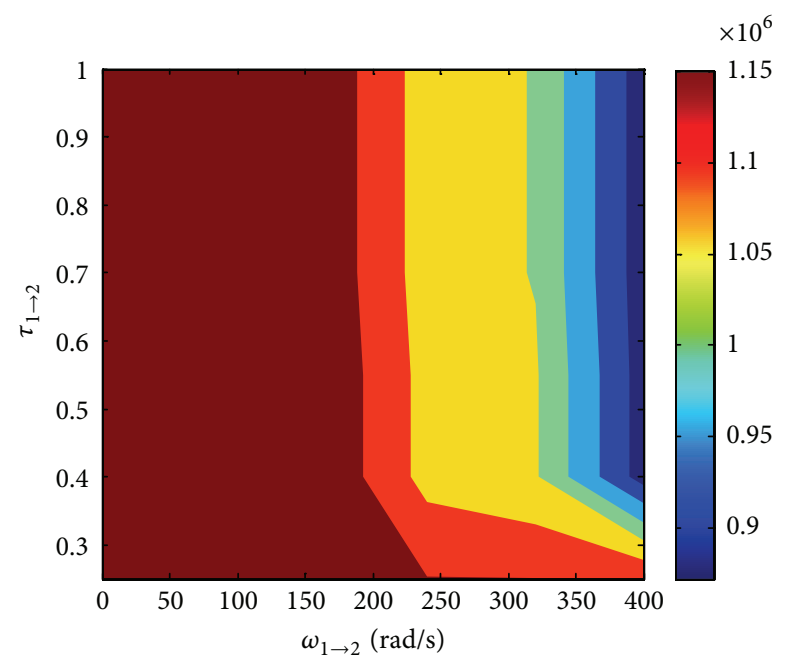

(a) Contour plot of energy losses (J) for NEDC

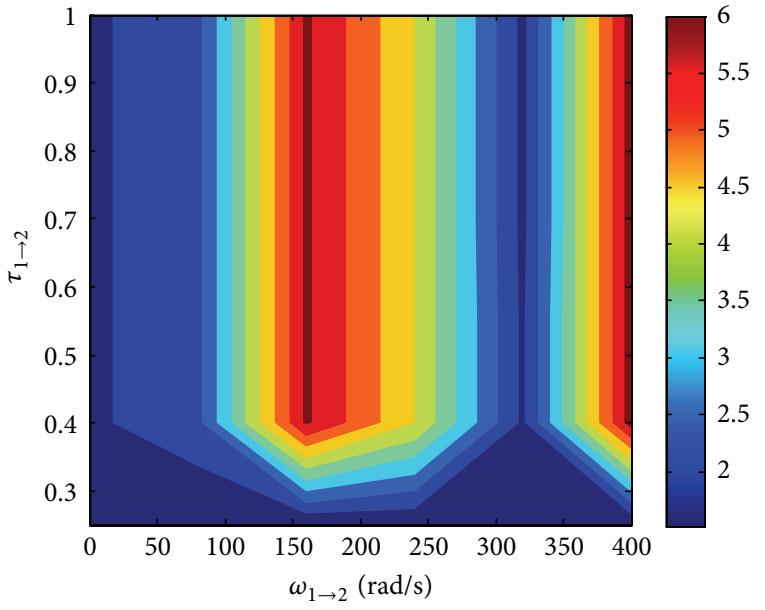

(b) Contour plot of $e_{v \mid \mathrm{MAX}}(\mathrm{km} / \mathrm{h})$ for NEDC

FIGURE 8: Contour plots of energy losses (a) and maximum $e_{v \mid \text { MAX }}$ (b) with $\omega_{1 \rightarrow 2}$ in the $x$-axis and $\tau_{1 \rightarrow 2}$ in the $y$-axis for the NEDC.

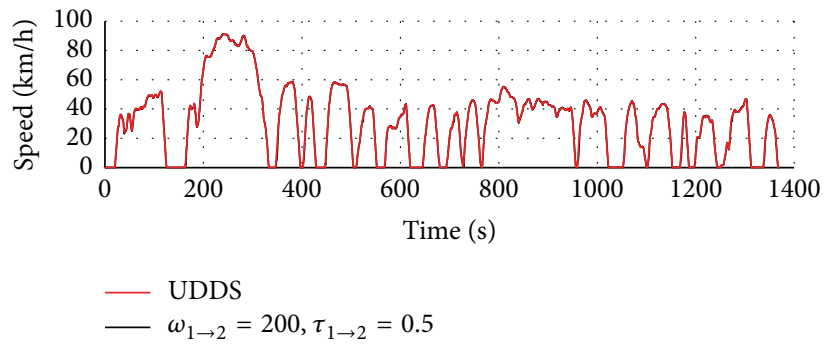

(a) Vehicle speed following the UDDS

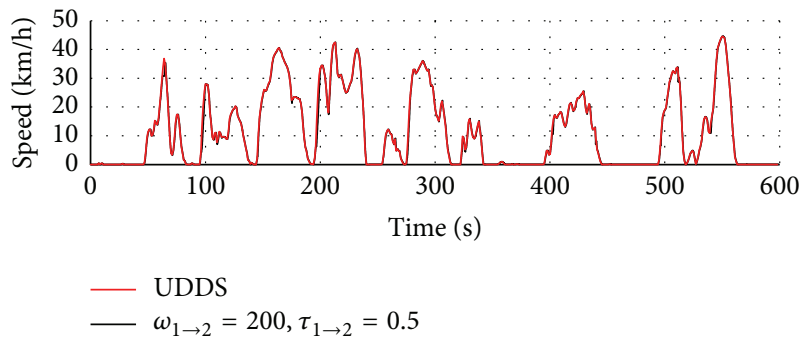

(b) Vehicle speed following the NYCC

FIGURE 9: PID controller vehicle speed to follow the UDDS (a) and the NYCC (b).

In this research, the maximum $e_{v}(t)$ produced in the driving cycle $\left(e_{v \mid \operatorname{MAX}}\right)$ is used as an indicator of drivability. An improved drivability is obtained when $e_{v \mid \text { MAX }}$ is maintained small. Figure 7(b) shows the speed of the electric motors while being controlled to produce the speed of the NEDC. Figure 7(c) shows the accumulated energy losses incurred by the simulated vehicle while following the driving cycle according to the model explained in Section 3.

The effect of $\omega_{1 \rightarrow 2}$ and $\tau_{1 \rightarrow 2}$ on the energy losses while the vehicle follows NEDC is illustrated in Figure 8(a). According to the figure, the energy losses increase when the values of $\omega_{1 \rightarrow 2}$ and $\tau_{1 \rightarrow 2}$ decrease. This situation corresponds to an early switch from OM 1 to OM 2 or when the driving cycle is handled almost completely in OM 2 . The maximum energy losses were found when $\omega_{1 \rightarrow 2}$ has a value of $80 \mathrm{rad} / \mathrm{s}$. The maximum energy losses found in this study at the end of the NEDC were of $1,199.753 \mathrm{~kJ}$. The minimum energy losses were found when $\omega_{1 \rightarrow 2}$ has a value of $400 \mathrm{rad} / \mathrm{s}$ and $\tau_{1 \rightarrow 2}>$ 0.70 . The minimum energy losses found in this study at the end of the NEDC were of $870.823 \mathrm{~kJ}$.

The effect of $\omega_{1 \rightarrow 2}$ and $\tau_{1 \rightarrow 2}$ on $e_{v \mid \mathrm{MAX}}$ while the vehicle follows NEDC is illustrated in Figure 8(b). According to the figure, $e_{v \mid \operatorname{MAX}}$ decreases when the values of $\omega_{1 \rightarrow 2}$ and $\tau_{1 \rightarrow 2}$ decrease. This situation corresponds to a better drivability, given that the driving cycle is handled almost completely in OM 2 (OM 3 did not appear in the entire driving cycle or appears at small values of speed). The best drivability was found when $\omega_{1 \rightarrow 2}$ has a value of $0 \mathrm{rad} / \mathrm{s}$ and $\tau_{1 \rightarrow 2}<0.25$, resulting in $e_{\nu \mid \operatorname{MAX}}$ of $1.52 \mathrm{~km} / \mathrm{h}$. The worst drivability was found when $\omega_{1 \rightarrow 2}=400 \mathrm{rad} / \mathrm{s}$ and $\tau_{1 \rightarrow 2}>0.4$, with a value of $e_{v \mid \operatorname{MAX}}=6.27 \mathrm{~km} / \mathrm{h}$. The plot reveals also a second worst case of drivability when $\omega_{1 \rightarrow 2}=160 \mathrm{rad} / \mathrm{s}$ and $\tau_{1 \rightarrow 2}>0.25$, with a value of $e_{v \mid \operatorname{MAX}}=6.08 \mathrm{~km} / \mathrm{h}$.

The Urban Dynamometer Driving Schedule (UDDS) and the New York City Cycle (NYCC) are driving cycles that present higher peak accelerations and lower speeds when compared with the NEDC [18]. The effect of the proposed control strategy under those driving cycles in terms of energy losses and drivability $\left(e_{v \mid \text { MAX }}\right)$ was also analyzed. The UDDS and the NYCC are shown in Figures 9(a) and 9(b), respectively, along with the speed profile produced by the control strategy applied in the simulated EV. The figure shows that the maximum speed achieved by the vehicle in the UDDS is $91.25 \mathrm{~km} / \mathrm{h}$, while for the NYCC it is of $44.6 \mathrm{~km} / \mathrm{h}$.

The effect of $\omega_{1 \rightarrow 2}$ and $\tau_{1 \rightarrow 2}$ on UDDS and NYCC is presented in Figure 10. For the UDDS the contour plot for the energy losses (Figure 10(a)) looks similar to the contour plot obtained for the NEDC (Figure 8(a)). The maximum 


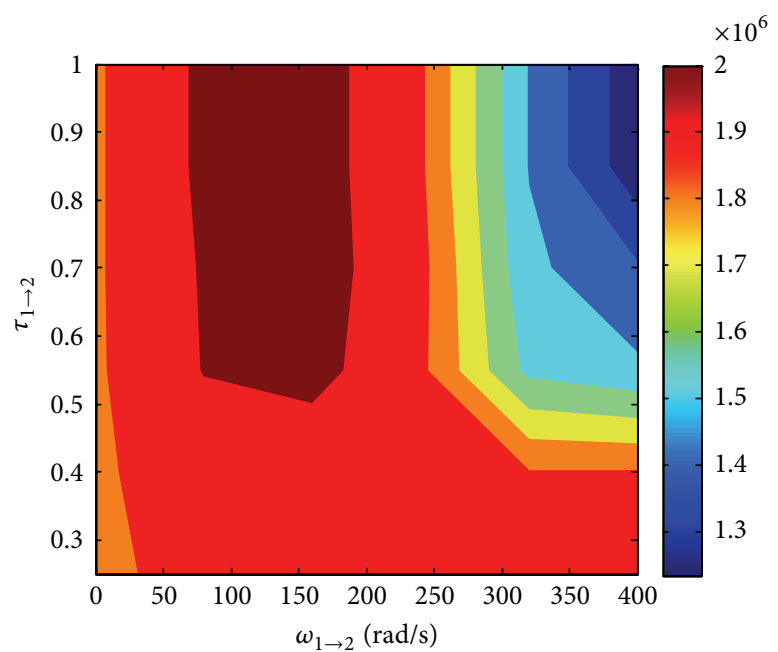

(a) Contour plot of energy losses (J) for UDDS

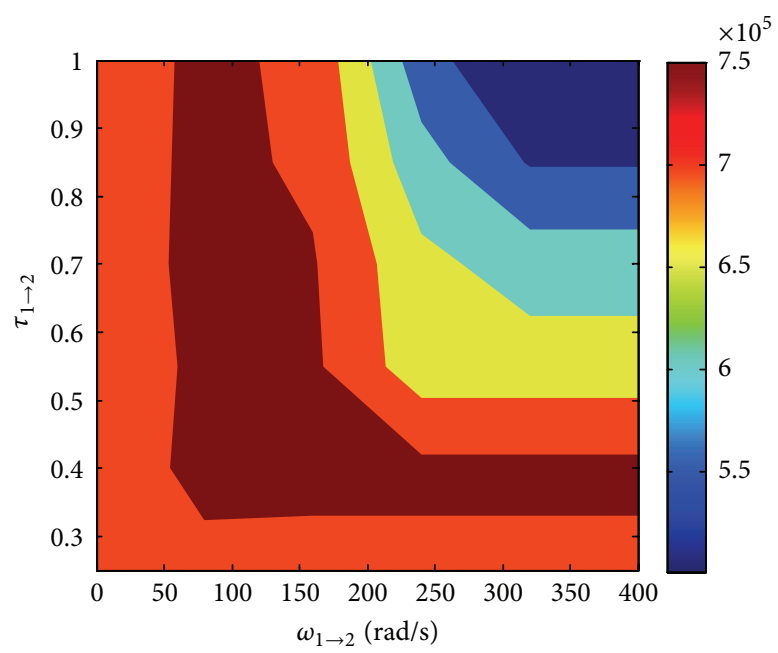

(c) Contour plot of energy losses (J) for NYCC

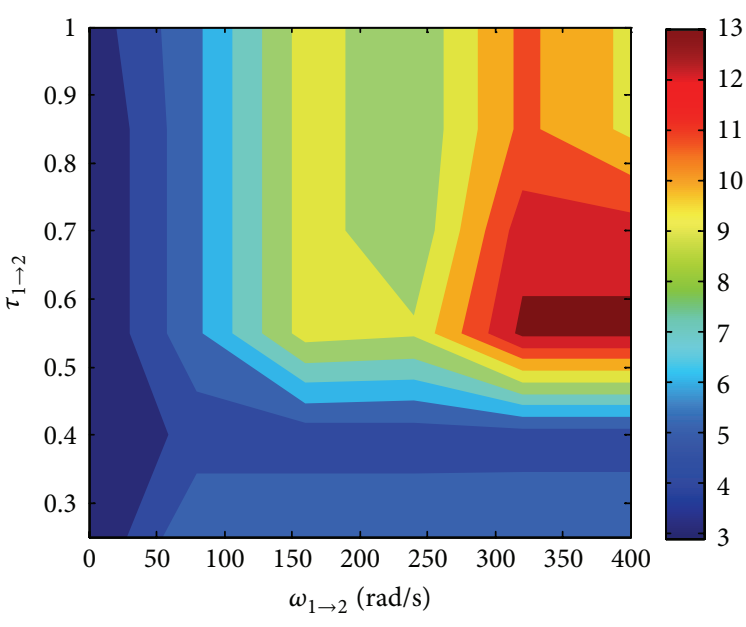

(b) Contour plot of $e_{v \mid \mathrm{MAX}}(\mathrm{km} / \mathrm{h})$ for UDDS

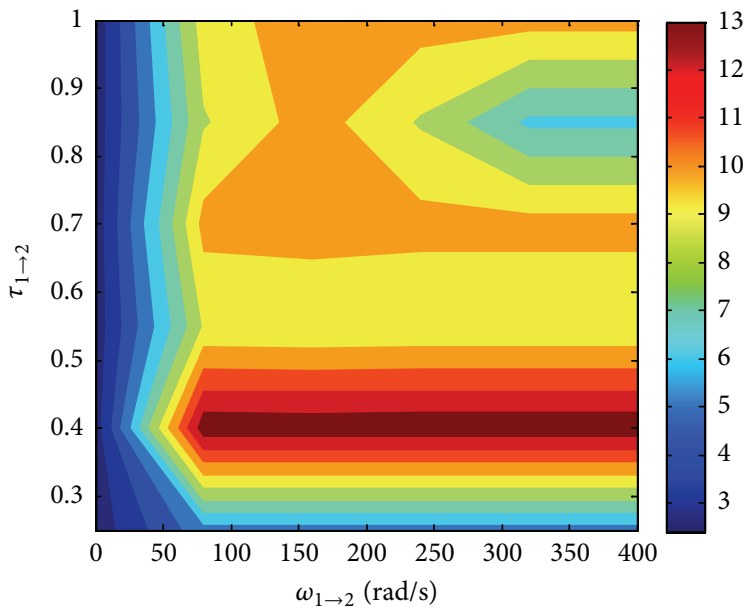

(d) Contour plot of $e_{v \mid \mathrm{MAX}}(\mathrm{km} / \mathrm{h})$ for NYCC

FIGURE 10: Contour plots for energy losses and $e_{v \mid \text { MAX }}$ for the driving cycles of UDDS and NYCC.

energy losses were found when $\omega_{1 \rightarrow 2}$ is less than $240 \mathrm{rad} / \mathrm{s}$ $(2,043.404 \mathrm{~kJ})$. The minimum energy losses were found when $\omega_{1 \rightarrow 2}$ has a value of $400 \mathrm{rad} / \mathrm{s}$ and $\tau_{1 \rightarrow 2}>0.85(1,233.674 \mathrm{~kJ})$. For drivability (Figure 10(b)), the results of the UDDS are similar to those of NEDC. The best drivability was found when $\omega_{1 \rightarrow 2}$ has a value of $0 \mathrm{rad} / \mathrm{s}$ and $\tau_{1 \rightarrow 2}<0.85\left(e_{v \mid \mathrm{MAX}}=\right.$ $2.89 \mathrm{~km} / \mathrm{h})$. The worst drivability was found when $\omega_{1 \rightarrow 2}$ has a value of $400 \mathrm{rad} / \mathrm{s}$ and $\tau_{1 \rightarrow 2}=0.55\left(e_{v \mid \mathrm{MAX}}=13.29 \mathrm{~km} / \mathrm{h}\right)$.

For the NYCC, according to Figure 10(c), the energy losses follow the same pattern as NEDC and UDDS, increasing in the zone of low $\omega_{1 \rightarrow 2}$ and $\tau_{1 \rightarrow 2}$ values $(765.012 \mathrm{~kJ})$ and decreasing when $\omega_{1 \rightarrow 2}$ and $\tau_{1 \rightarrow 2}$ are high $(501.146 \mathrm{~kJ})$. For the drivability, the NYYC presented the potential worst case of drivability between the analyzed driving cycles with $e_{v \mid \operatorname{MAX}}=13.72 \mathrm{~km} / \mathrm{h}$ found when $\omega_{1 \rightarrow 2}$ has a value of more than $80 \mathrm{rad} / \mathrm{s}$ and $\tau_{1 \rightarrow 2}=0.4$. The best drivability was found in the same zone as the UDDS and NEDC, when $\omega_{1 \rightarrow 2}$ and $\tau_{1 \rightarrow 2}$ have low values $\left(e_{v \mid \operatorname{MAX}}=2.40 \mathrm{~km} / \mathrm{h}\right)$.
5.2. Discussion. The energy losses in all modes were reduced when a high transition speed $\left(\omega_{1 \rightarrow 2}\right)$ was set in combination with a high transition torque request signal $\left(\tau_{1 \rightarrow 2}\right)$. This indicates that energy losses were reduced when the driving cycle is handled most of the time in OM 1, with only one electric motor. To handle the whole driving cycle in OM 1 is only possible for the NYCC because of its low maximum speed. For the UDDS and mainly for NEDC, the switching from OM 1 to OM 2 was necessary to achieve the speeds above $61.7 \mathrm{~km} / \mathrm{h}$, which correspond to the electric motor maximum speed (of $800 \mathrm{rad} / \mathrm{s}$ ) in OM 1.

The differences in energy losses can be explained by analyzing the efficiency map of the motors and the zones in which the operation points are located under different values of $\omega_{1 \rightarrow 2}$ and $\tau_{1 \rightarrow 2}$. Figure 11 illustrates this by showing the efficiency map of the motor with the operation points produced superposed, when NEDC is followed. Figure 11(a) uses the parameters $\omega_{1 \rightarrow 2}$ and $\tau_{1 \rightarrow 2}$ with values of $400 \mathrm{rad} / \mathrm{s}$ 


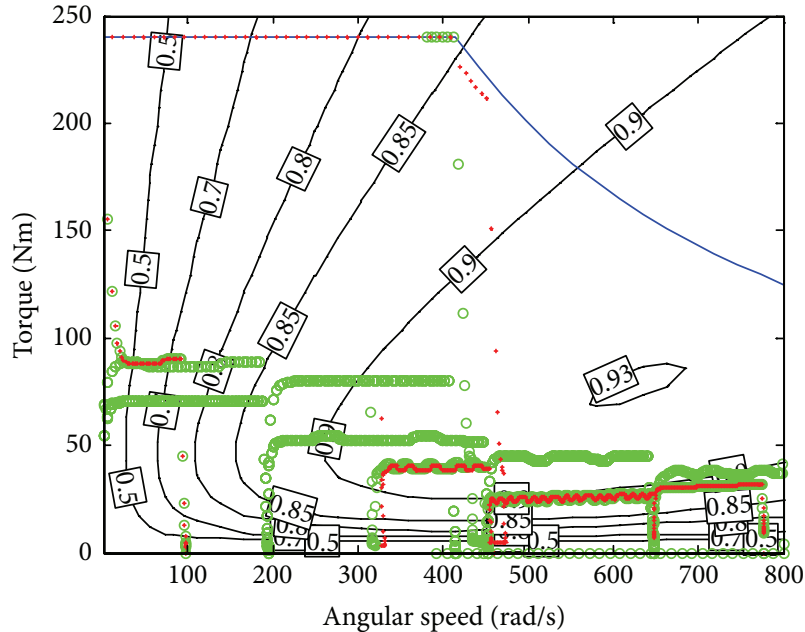

- Electric motor 1

+ Electric motor 2

(a) $\omega_{1 \rightarrow 2}=400 \mathrm{rad} / \mathrm{s}, \tau_{1 \rightarrow 2}=0.55$, NEDC

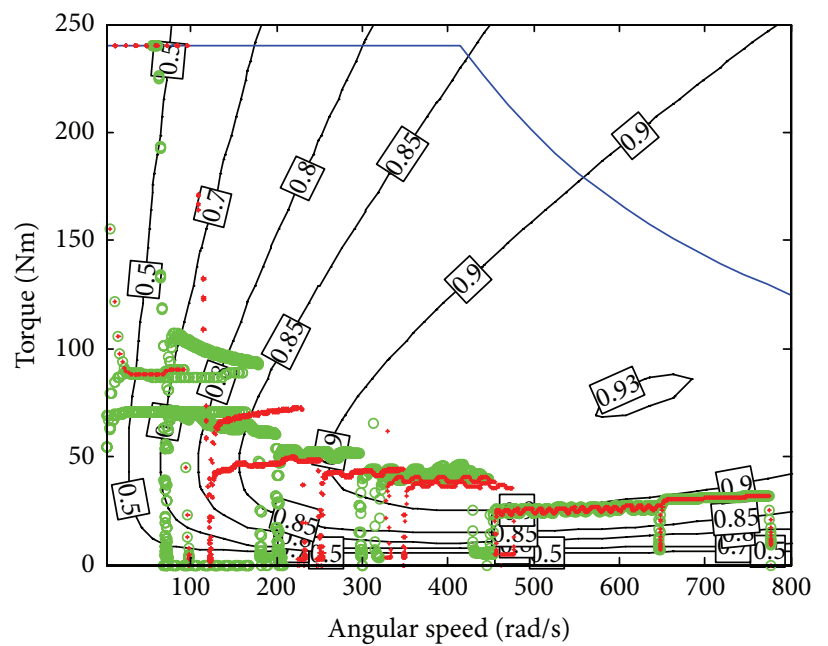

- Electric motor 1

+ Electric motor 2

(b) $\omega_{1 \rightarrow 2}=80 \mathrm{rad} / \mathrm{s}, \tau_{1 \rightarrow 2}=0.4$, NEDC

FIGURE 11: Operation points of the two electric motors for the NEDC, superposed in the electric motor efficiency map.

and 0.55 , respectively. Figure $11(\mathrm{~b})$ shows the operation points produced when $\omega_{1 \rightarrow 2}=80$ and $\tau_{1 \rightarrow 2}=0.4$. Comparing the figures, (a) has more operation points in the high speed zone than (b). The high speed zone in the efficiency map corresponds to the higher efficiency, while zones of low speed present also low efficiencies. This produced a difference in energy losses of $318.617 \mathrm{~kJ}$ less between the operation points of (a) with respect to (b). Another observation that can be drawn from Figure 11 is the low utilization of the torque range by the NEDC. Driving cycles with higher accelerations require higher torques. Also, variations in the design of the powertrain can include different transmission gear ratios (which modify the torque requirements in the motors) and different sizes of electric motors to get a better fit of the operation points.

In this work, two electric motors of the same characteristics were used. The effect of having two electric motors with different efficiency maps or size would be that the control strategy would have to account for two types of OM 1, depending on which motor is actuated and which motor is locked. Each motor could offer efficiency advantages in certain conditions of torque and speed, which would add flexibility to the system. On the other hand, two motors of the same characteristics simplify the control strategy and allow fault tolerant traction in the case of failure of any of the electric motors: independently of the faulty motor, any of the motors can continue operating in OM 1 providing the vehicle with the same output torque (however with the limitation in maximum vehicle speed that appears with OM 1).

According to the results, high $\omega_{1 \rightarrow 2}$ and high $\tau_{1 \rightarrow 2}$ combination produces less energy losses but also produces the highest $e_{v \mid \text { MAX }}$ for the driving cycles NEDC, UDDS, and NYCC.

\section{Conclusions}

A control strategy for a dual motor propulsion system for EVs is established in this work. The control strategy receives the torque demand and distributes it to the two electric motors to provide the desired acceleration and speed. The objective of the control strategy is to allow the desired acceleration while maintaining low energy losses.

The proposed control strategy is based on rules, with feasibility to be implemented in a real time control system. The control strategy inputs are the current speed of the electric motors and the torque demand signal $(\tau)$. The control strategy can be tuned using two parameters: the transition speed $\left(\omega_{1 \rightarrow 2}\right)$ and the transition torque request signal $\left(\tau_{1 \rightarrow 2}\right)$. These parameters define when to switch from the use of one motor only (which is identified as OM 1) to two motors (identified as OM 2). The switching produces a transition mode (OM 3), which produces a brief period of coasting of about $1.7 \mathrm{~s}$ in this work. This period of coasting can affect drivability by producing a difference between the desired speed and the actual speed. This error was calculated and analyzed.

The effect of $\omega_{1 \rightarrow 2}$ and the transition torque request signal $\tau_{1 \rightarrow 2}$ on energy losses and drivability was studied by running simulations of the speed and energy losses produced by the electric motors in an EV. The simulations made use of three of the most popular driving cycles: NEDC, UDDS, and NYCC. The results show that $\omega_{1 \rightarrow 2}$ and $\tau_{1 \rightarrow 2}$ have a significant effect on the energy losses and drivability. According to the results, the combination of high $\omega_{1 \rightarrow 2}$ and high $\tau_{1 \rightarrow 2}$ provides the best results overall in energy savings in the analyzed driving cycles. The drivability as studied here, using the indicator $e_{v \mid \mathrm{MAX}}$, is affected by driving cycles with 
high accelerations and also when the shifting between modes is produced at higher speeds.

\section{Conflict of Interests}

The authors declare that there is no conflict of interests regarding the publication of this paper.

\section{References}

[1] E. Helmers and P. Marx, "Electric cars: technical characteristics and environmental impacts," Environmental Sciences Europe, vol. 24, no. 4, article 14, 2012.

[2] J.-S. Lee, S. T. Kim, R. Cao et al., "Metal-air batteries with high energy density: Li-air versus Zn-air," Advanced Energy Materials, vol. 1, no. 1, pp. 34-50, 2011.

[3] A. F. Burke, "Batteries and ultracapacitors for electric, hybrid, and fuel cell vehicles," Proceedings of the IEEE, vol. 95, no. 4, pp. 806-820, 2007.

[4] K. Yoshida, S. Tomonari, H. Yoshioka, S. Tanaka, D. Satoh, and M. Esashi, "High energy density miniature electrical and thermal power source using catalytic combustion of butane," in Proceedings of the 17th IEEE International Conference on Micro Electro Mechanical Systems (MEMS '04), pp. 316-321, January 2004.

[5] J. Meschke, M. Kurz, C. Schoenwald, A. Tornow, R. Hackl, and M. Flume, "Advanced lightweight design for electric vehiclesALIVE," in Proceedings of the Transport Research Arena on the 5th Conference: Transport Solutions from Research to Deployment (TRA '14), Paris, France, April 2014.

[6] A. Khaligh and Z. Li, "Battery, ultracapacitor, fuel cell, and hybrid energy storage systems for electric, hybrid electric, fuel cell, and plug-in hybrid electric vehicles: state of the art," IEEE Transactions on Vehicular Technology, vol. 59, no. 6, pp. 28062814, 2010.

[7] J. De Santiago, H. Bernhoff, B. Ekergård et al., "Electrical motor drivelines in commercial all-electric vehicles: a review," IEEE Transactions on Vehicular Technology, vol. 61, no. 2, pp. 475-484, 2012.

[8] S. Zhang, C. Zhang, G. Han, and Q. Wang, "Optimal control strategy design based on dynamic programming for a dualmotor coupling-propulsion system," The Scientific World Journal, vol. 2014, Article ID 958239, 9 pages, 2014.

[9] P. D. U. Coronado and H. Ahuett-Garza, "Analysis of energy efficiency and driving range of electric vehicles equipped with a bimotor architecture propulsion system," International Journal of Electric and Hybrid Vehicles, vol. 6, no. 2, pp. 152-177, 2014.

[10] Y. Wang and D. Sun, "Powertrain matching and optimization of dual-motor hybrid driving system for electric vehicle based on quantum genetic intelligent algorithm," Discrete Dynamics in Nature and Society, vol. 2014, Article ID 956521, 11 pages, 2014.

[11] R. M. Patil, Z. Filipi, and H. K. Fathy, "Comparison of supervisory control strategies for series plug-in hybrid electric vehicle powertrains through dynamic programming," IEEE Transactions on Control Systems Technology, vol. 22, no. 2, pp. 502-509, 2014.

[12] E. Dinçmen and B. A. Güvenç, "A control strategy for parallel hybrid electric vehicles based on extremum seeking," Vehicle System Dynamics, vol. 50, no. 2, pp. 199-227, 2012.

[13] J. Larminie and J. Lowry, Electric Vehicle Technology Explained, John Wiley \& Sons, New York, NY, USA, 2003.
[14] A. Elmarakbi and A. Morris, "Modelling and analyzing electric vehicles with geared transmission systems: enhancement of energy consumption and performance," International Journal of Engineering Research \& Technology, vol. 2, pp. 1215-1254, 2013.

[15] A. Elmarakbi, Q. Ren, R. Trimble, and M. Elkady, "Performance analysis of hybrid and full electrical vehicles equipped with continuously variable transmissions," Advances in Automobile Engineering, vol. 2, article 103, 2013.

[16] K. Sedef, A. Maheri, A. Daadbin, and M. Yilmaz, "A comparative study of the performance of DC permanent magnet and AC induction motors in urban electric cars," in Proceedings of the 2nd International Symposium on Environment Friendly Energies and Applications (EFEA '12), pp. 100-105, Newcastle upon Tyne, UK, June 2012.

[17] L. Puhui, X. Tong, and Z. Xuanbai, "Vehicle drivability evaluation and pedal-acceleration response analysis," International Journal on Advances in Information Sciences and Service Sciences, vol. 5, no. 10, pp. 506-513, 2013.

[18] B. M. Geller, T. H. Bradley, and B. M. Geller, "Analyzing drive cycles for hybrid electric vehicle simulation and optimization," Journal of Mechanical Design, vol. 137, no. 4, Article ID 041401, 14 pages, 2015. 


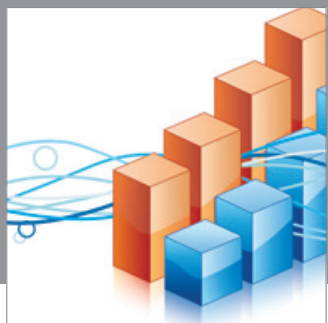

Advances in

Operations Research

mansans

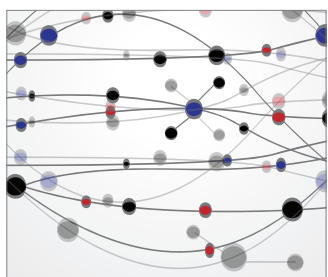

The Scientific World Journal
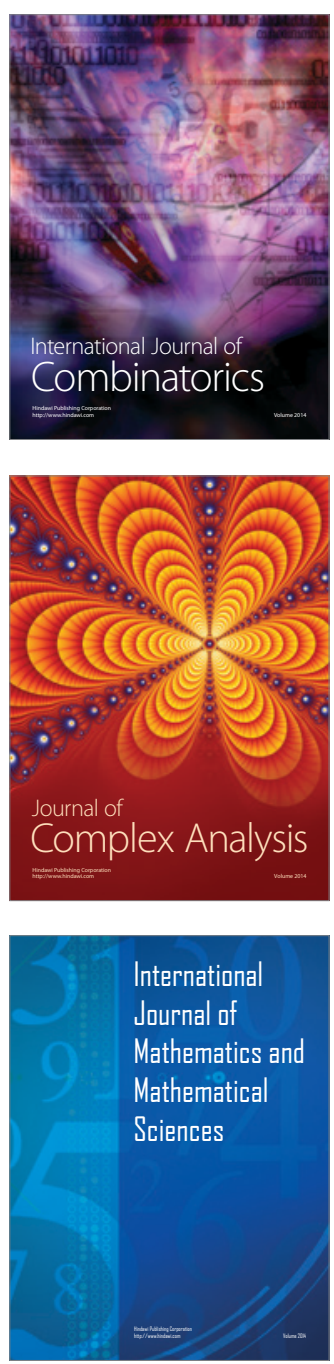
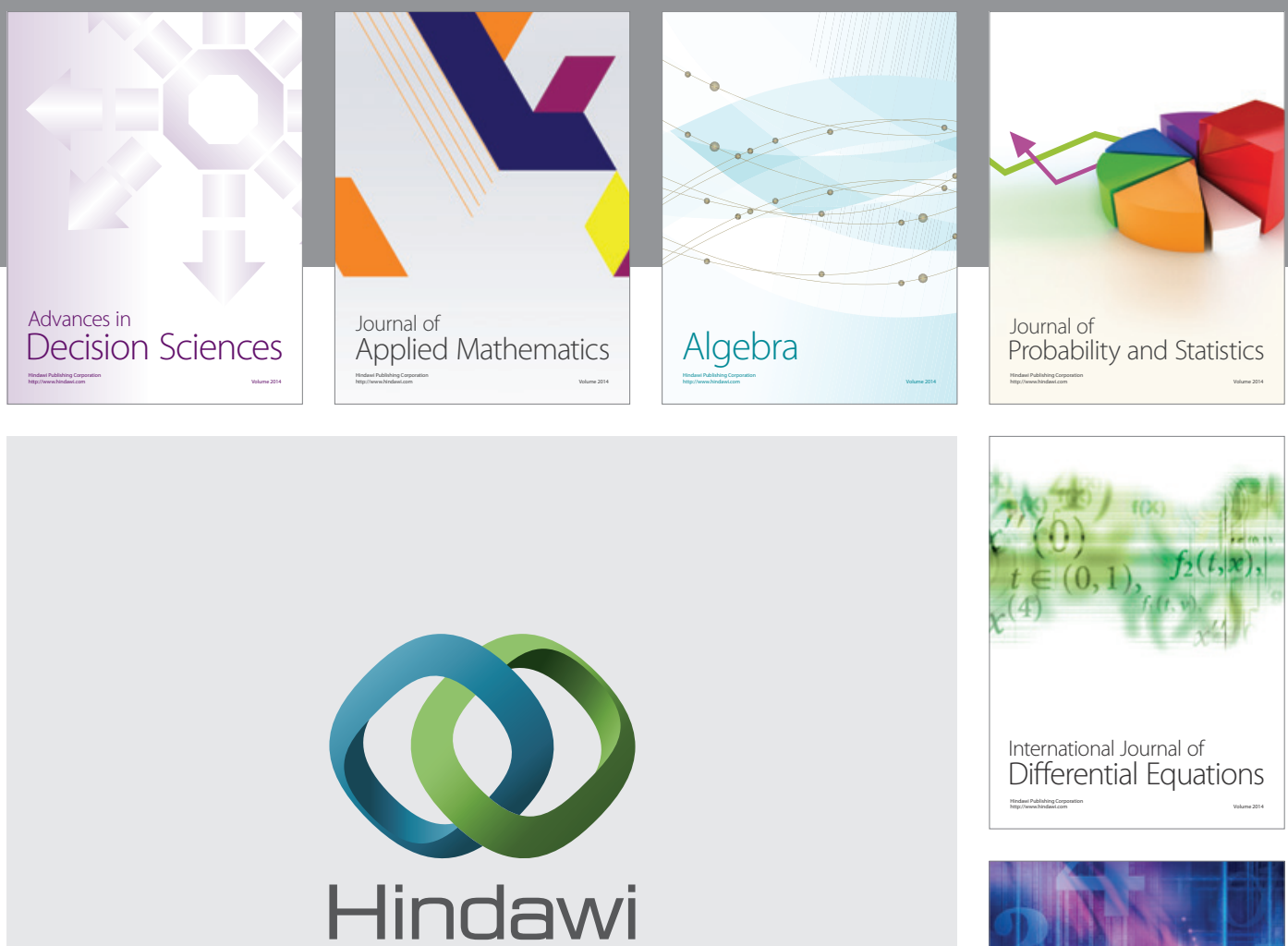

Submit your manuscripts at http://www.hindawi.com
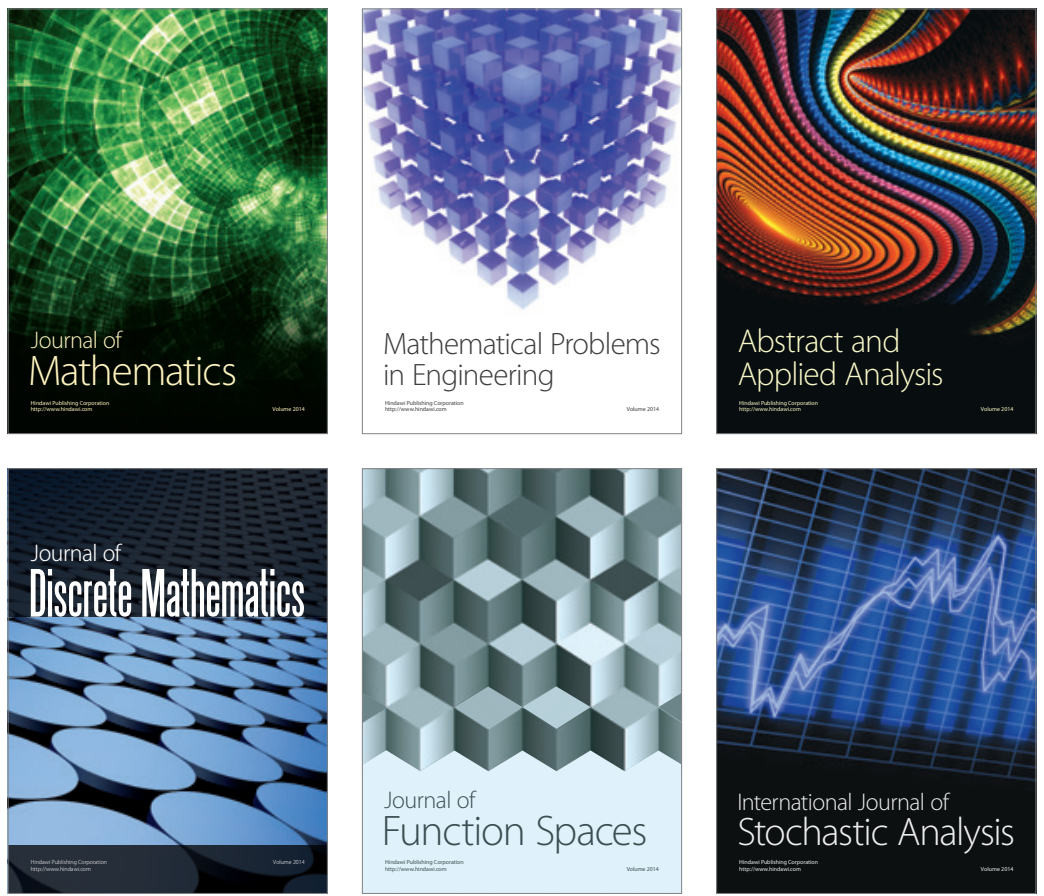

Journal of

Function Spaces

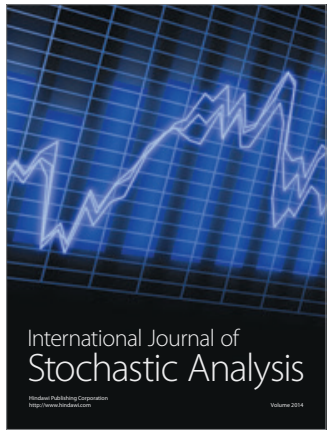

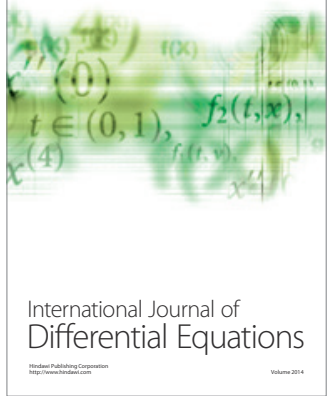
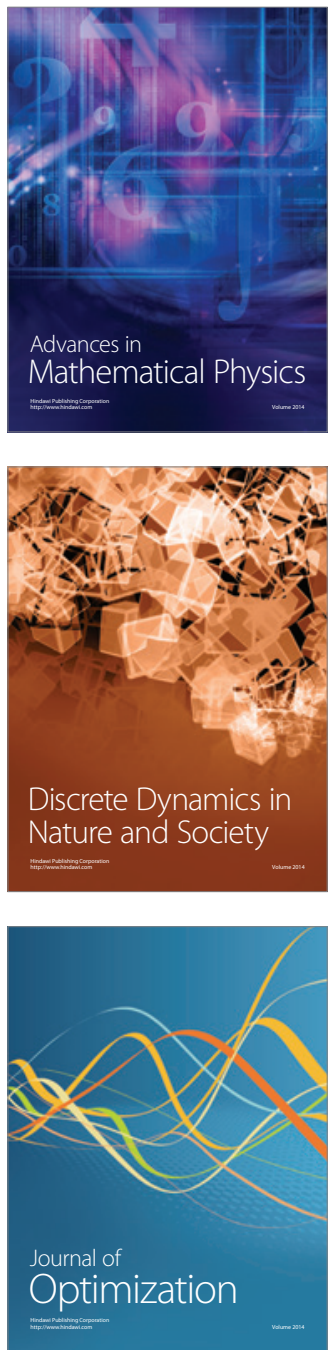